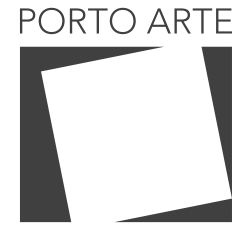

Revista de Artes Visuais

v. $25 n .43$ Jan/jun 2020 e-ISSN: 2179-8001

\title{
Colocar imagens à prova: entrevista com Ionaldo Rodrigues
}

Put images to the test: interview with Ionaldo Rodrigues

\section{Gil Vieira Costa}

ORCID: 0000-0002-2893-7343

Universidade Federal do Sul e Sudeste do Pará, Brasil

Ionaldo Rodrigues

Fundação Cultural do Pará, Brasil

ORCID: 0000-0001-8517-3397

\section{Resumo}

O artista contemporâneo Ionaldo Rodrigues é entrevistado por Gil Vieira Costa, tratando de diversos temas relacionados à produção artística, como: relações entre fotografia e instalação em suas obras mais recentes; fotografia e mercado de arte; relações entre imagem visual e palavra escrita; arte e engajamento social e político; entre outros. Ionaldo Rodrigues fornece informações sobre o processo de criação, produção e exibição de algumas obras suas, que podem ser consideradas de enorme relevância para a compreensão aprofundada sobre seu trabalho.

Palavras-chave

Arte contemporânea. Imagem. Fotografia. Instalação. Política.

\begin{abstract}
Contemporary artist Ionaldo Rodrigues is interviewed by Gil Vieira Costa, dealing with various themes related to artistic production, such as: relations between photography and installation in his most recent works; photography and art market; relations between visual image and written word; art and social and political engagement; among others. Ionaldo Rodrigues provides information about the creation, production and exhibition process of some of his works, which can be considered of enormous relevance for the in-depth understanding of his work.
\end{abstract}

Keywords

Contemporary art. Image. Photography. Installation. Politics. 


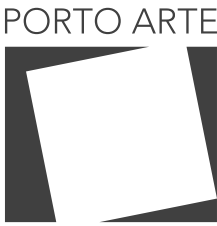

Revista de Artes Visuais

V.25 n. 43 Jan/jun 2020 e-ISSN: 2179-8001
Figura 1: Ionaldo Rodrigues Drenagem, 2016, instalação. Fonte: VII Prêmio Diário Contemporâneo de Fotografia fotografia de Ionaldo Rodrigues.
Ionaldo Rodrigues (Belém/PA, 1985) é sociólogo, formado pela Universidade Federal do Pará (2003-2008). Em 2004 realizou cursos livres de fotografia na Associação Fotoativa, instituição em que se engajou enquanto artista. Em 2007, foi um dos contemplados com a Bolsa de Pesquisa em Arte do IAP (Instituto de Artes do Pará), com a série Botânica do Asfalto. Desde então participa de mostras competitivas e outras exposições coletivas, além de ter realizado a individual Rebotalho, em 2015, na Kamara Kó Galeria em Belém. Em 2018 foi um dos premiados no IX Prêmio Diário Contemporâneo de Fotografia, com a instalação C Nova Feira. Em 2019 foi um dos artistas convidados no $38^{\circ}$ Arte Pará, com a instalação Arar o solo. Seu trabalho maneja ideias como história, paisagem e cidade.

Nesta entrevista, Ionaldo Rodrigues aborda aspectos de sua produção, em especial das obras mais recentes. A conversa foi realizada por meio de troca de e-mails, entre 27 de março e 31 de maio de 2020. Por um lado, tal método resultou em uma entrevista menos espontânea e fluida do que o habitual; por outro, garantiu a entrevistador e entrevistado o tempo adequado para reflexão e escrita, e maior controle de ambos sobre o resultado. A proposta buscou ocupar, portanto, o espaço limítrofe e dialógico entre ensaio e entrevista, e entre crítica e "autocrítica" (a reflexão do artista sobre seu trabalho). Algumas notas de rodapé foram inseridas no decorrer da entrevista, para apresentar descrições de trabalhos de Ionaldo Rodrigues e outras informações relevantes.

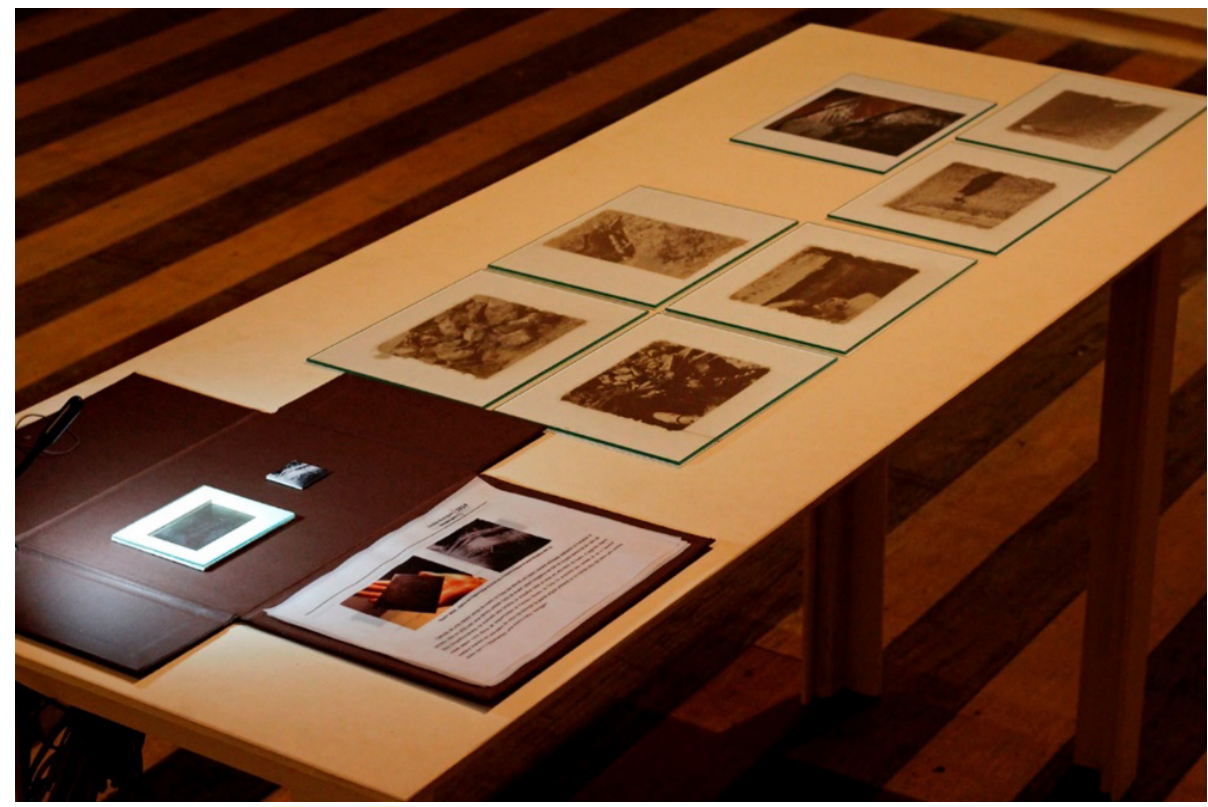

\section{Gil Vieira Costa:}

Parece haver, na tua produção recente, uma passagem da prática fotográfica mais convencional para uma prática no campo da instalação, que já estava presen- 


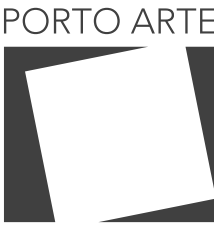

Revista de Artes Visuais

v. $25 n .43$ Jan/jun 2020 e-ISSN: 2179-8001
Figura 2: Ionaldo Rodrigues, $C$ Nova Feira, 2018, instalação. Fonte: IX Prêmio Diário Contemporâneo de Fotografia, fotografias de Pedro Rodrigues. te em obras como Drenagem (2014/2016) (fig. 01). ${ }^{1}$ Esse uso da instalação artística traz algumas implicações, que eu gostaria de discutir, para iniciar nossa conversa. Uma delas diz respeito à tua atuação como fotógrafo: o caráter estético da "boa foto", tão valorizado e tão associado à fotografia contemporânea em Belém, disputa terreno com a fotografia como documentação, registro "objetivo".
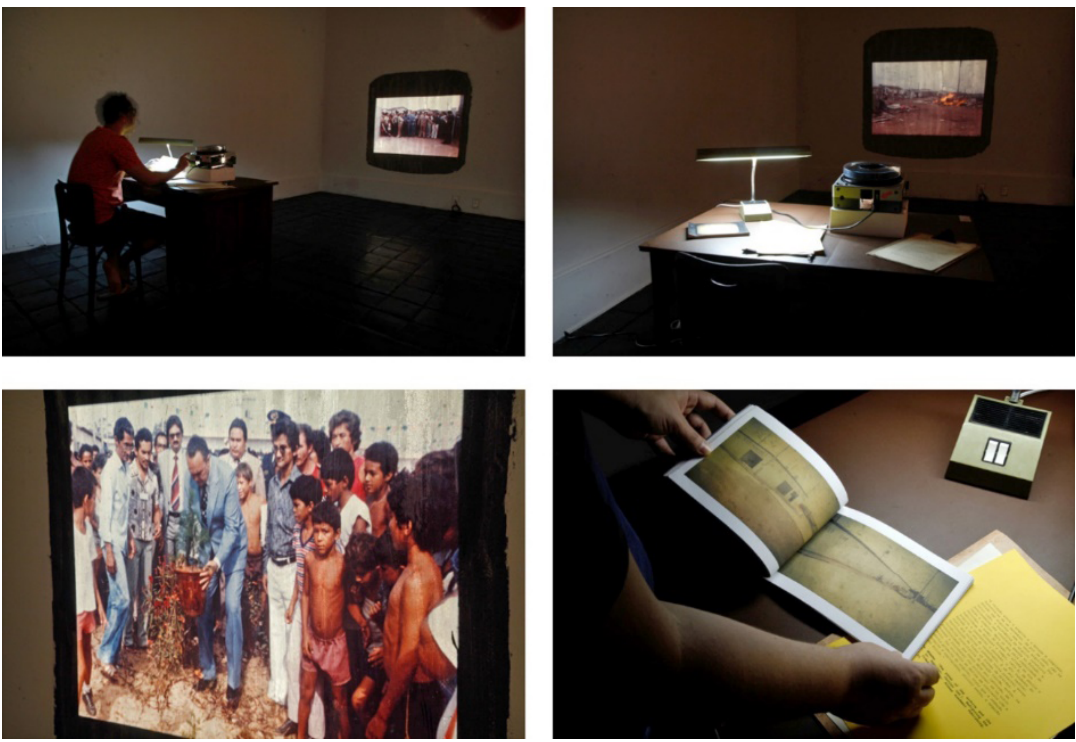

De certa forma, nas obras C Nova Feira ${ }^{2}$ e Arar o solo³, o "olhar do fotógrafo" diz menos respeito a uma educação visual e sensível, que capta traduz o mundo por meio do "estilo" do fotógrafo, e mais sobre as coisas que o artista seleciona e expõe - algo que já estava latente mesmo numa série do início da tua carreira, como Botânica do

\footnotetext{
1- Drenagem (2014/2016) é um conjunto de documentos fotográficos e uma publicação (memorial). A primeira montagem, de 2014, foi pensada só com as imagens em molduras na parede. A montagem de 2016 (fig. 01) apresenta o trabalho integralmente disposto em uma mesa. A obra aborda associações entre a materialidade urbana e a materialidade fotográfica. Apresenta imagens de pavimentos e aberturas para elementos subterrâneos através de diferentes processos fotográficos (daguerreótipo, câmera escura/pinhole, papel salgado e fotografia digital).

2- C Nova Feira (2018) é uma instalação composta por: mobiliário (cadeira e mesa de escritório); aparelho projetor de slides, contendo 43 diapositivos; mancha de cimento cru na parede para projeção; instruções para uso do projetor; uma ficha de indexação de arquivo sobre o conjunto de diapositivos; publicação fotográfica realizada a partir da reprodução do conjunto de diapositivos; e um parágrafo sobre a relação entre arquivo e Estado, extraído de texto de Achille Mbembe. O conjunto de diapositivos registra o processo de construção, desmontagem da feira antiga e inauguração da Feira da Cidade Nova 4, em Ananindeua, região metropolitana de Belém, na primeira metade da década de 1980. Não possui autoria identificada. 0 material foi arquivado no setor de Audiovisual da Fundação Curro Velho, em 2014, antes alocado no almoxarifado da instituição. Não há registro de doação, tombo ou data de entrada.

3- Arar o solo (2019) é uma instalação composta por: mobiliário (cadeira, mesa e parede falsa de madeira compensada); quatro macrofotografias de um verso de João de Jesus Paes Loureiro em moldura backlight: várias reproduções de livros, jornais e outras publicações, fixadas na parede ou na mesa; publicações fotográficas trazendo diferentes tipos de reprodução de livros de Paes Loureiro e outros documentos, dispostos sobre a mesa. A obra trata principalmente sobre o livro Tarefa, de Paes Loureiro, cuja primeira tiragem fo confiscada e destruída no contexto do golpe civil-militar de 1964. Inclui a fotocópia da edição fac-similar. realizada em 1989 a partir de exemplar sobrevivente do livro publicado em 1964
} 


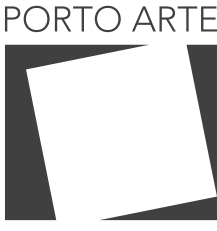

Revista de Artes Visuais

$\vee 25 n .43$

Jan/jun 2020 e-ISSN: 2179-8001

asfalto. ${ }^{4} \mathrm{O}$ fato talvez aponte que a tua produção percorra simultaneamente dois caminhos: o artista criador, que fabrica imagens trabalhando com a forma, a técnica, o olhar; e o artista apropriador, que intercepta as imagens e reorienta seu sentido ou direção.

\section{Ionaldo Rodrigues:}

Eu acredito que os dois trabalhos, C Nova Feira (fig. 02) e Arar o Solo (fig. 03), possuem uma ligação forte com o trabalho de digitalização do arquivo fotográfico analógico do Curro Velho. ${ }^{5}$ Iniciei esse trabalho em 2016, mesmo período em que me afastei progressivamente de dois campos de atuação em relação à fotografia: produção cultural, a que estive envolvido no período da Fotoativa, e na produção de fotografia documental no próprio Curro Velho, produção que não cessou completamente, mas ficou mais rarefeita devido a uma brutal falta de valorização da memória institucional, o que pra mim é mais um sintoma do abandono do próprio projeto do Curro Velho e de demais instituições de educação, cultura e arte no contexto regional e nacional.

A gente sabe que o trabalho no arquivo segue protocolos e procedimentos vindo dos profissionais e das instituições que acumulam conhecimento sobre a maneira de preservar e tornar os documentos disponíveis aos possíveis fluxos de ativação do conteúdo e da forma deles. Nas minhas tentativas de seguir esses protocolos e realizar um trabalho profissional com o arquivo do Curro, sou muitas vezes atravessado pelo mesmo espanto ou suspensão que já senti em períodos entre a produção de uma imagem e a "revelação" dela quando percebida com atenção pela primeira vez ou redescoberta depois de muitas vistas. As questões levantadas por essa latência, na duração e no contexto de um arquivo que não é o meu arquivo autoral de imagens, são estimulantes e reafirmam a radicalidade de ideias e aprendizados com práticas de laboratório que pude tomar contato durante meu envolvimento com o fotográfico, dois exemplos: as relações entre automatismo, inconsciente ótico e montagem na teoria benjaminiana ${ }^{6} \mathrm{e}$ a reflexão do Patrick Pardini sobre alteridade e autoria na criação artística e no campo fotográfico. ${ }^{7}$ Essas duas fontes teóricas e conceitualmente muito sofisticadas, ganham uma concretude muito viva em procedimentos rotineiros de quem produz, arquiva, lê e quer dizer algo a partir de fotografias.

No caso das instalações, eu acho que encontrei nelas uma maneira de organizar a montagem dos elementos que constituem os trabalhos e, ao mesmo tempo, disponibilizar os dispositivos que tornam esses elementos (livros, impressos, slides fotográficos,

\footnotetext{
4- Botânica do asfalto (2007/2015) é um ensaio que aborda tensões entre história natural e história social a partir de impressões em cianotipia (processo fotográfico desenvolvido no século XIX a partir de sais férricos e que produz imagens em tons azuis por exposição do suporte sensibilizado com químico à luz do sol (UV) em contato com a matriz/negativo, gerando então a cópia positiva após revelação). 0 ensaio foi primeiramente montado como caixa portfólio e impressões emolduradas e, em 2015, parte foi editada como múltiplos em pequeno formato pelo selo Prova Impressa.

5- Inicialmente Fundação Curro Velho (1991-2014), com sede em Belém, a partir de 2015 se torna o Núcleo de Oficinas Curro Velho, vinculado à Fundação Cultural do Pará. Ionaldo Rodrigues integra o corpo técnico da instituição desde 2010

6- Walter Benjamin et al., Benjamin e a obra de arte: técnica, imagem, percepção, tradução de Marijane Lisboa e Vera Ribeiro, organização de Tadeu Capistrano, Rio de Janeiro: Contraponto, 2012.

7- Patrick Pardini, Criação fotográfica: a experiência do outro e a dissolução da autoria, versão revista e ampliada da palestra Autografia 01: Fotografia e Autoria, realizada no IX Colóquio Fotografia e Imagem: Autografias, Belém: NPD/NCD Fotoativa, 2014. Disponível em: <http://www.fotoativa.org.br/wp-content/ uploads/2014/10/texto-CriacaoFotografica_PatrickPardini.pdf>
} 


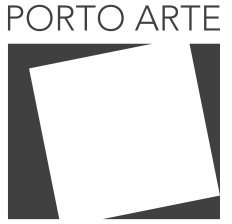

Revista de Artes Visuais

v. $25 n .43$ Jan/jun 2020 e-ISSN: 2179-8001

Figura 3: Ionaldo Rodrigues, Arar o solo, 2019, instalação Fonte: $38^{\circ}$ Arte Pará, fotografia de Gil Vieira Costa

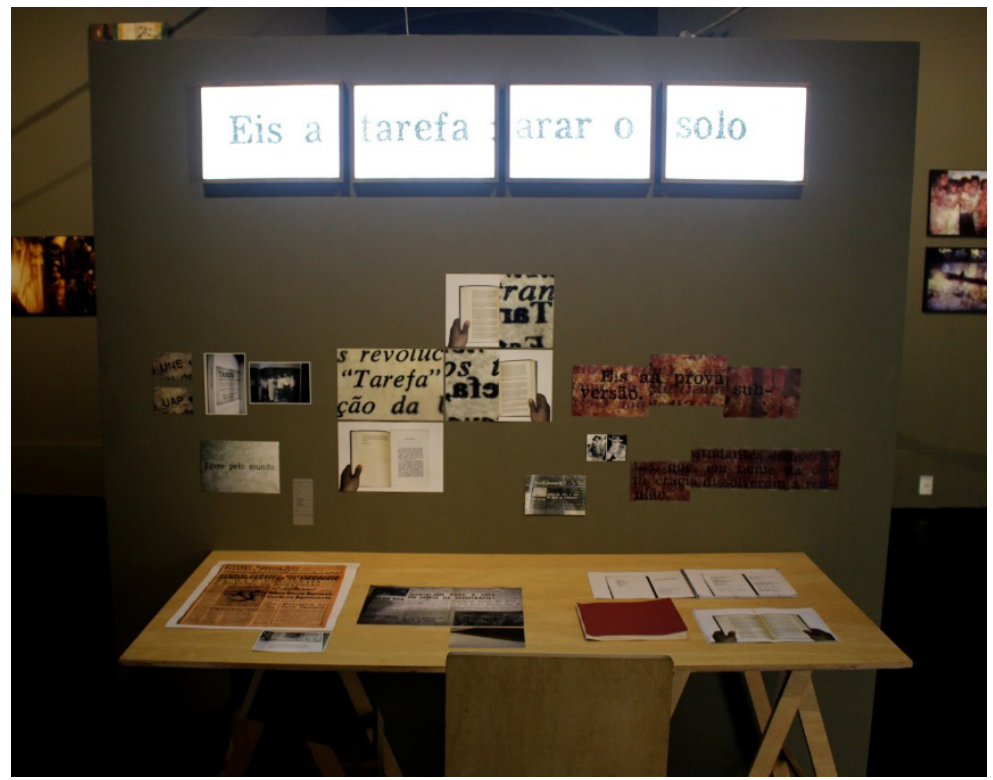

reproduções, mobiliário, aparelhos, etc.) documentos sensíveis a leituras e apropriações, distanciamentos e aproximações.

A possibilidade de propor um espaço e um tempo de manipulação dos documentos que pretende abrir ao público os artifícios acionados por um arquivista, no caso do C Nova Feira, e de um leitor, no caso do Arar o solo, acompanham o desejo de revelar os artifícios que atuaram na produção desses mesmos documentos. No caso das imagens, esse processo de naturalização do artifício é muito estimulado por uma sensibilidade formada nos protocolos positivistas de afirmação do documento vinculando sua autoridade e validação à originalidade e leitura única, oficial.

Nesse sentido, as instalações me proporcionaram a possibilidade de reunir um número maior de situações em que eu pude colocar esses documentos à prova. Reproduzir, em livros, papéis avulsos, fac-símiles, caixas de luz, fichas de indexação, intervir na parede de projeção, geralmente neutra, com cimento, explorar recursos óticos, fragmentos em macrofotografia, transparência/opacidade dos suportes em determinado tipos de iluminação etc. Junto a seleção e exibição, há uma tentativa de evidenciar que a realidade que preexistiu a produção desses documentos (todo o contexto da Feira da Cidade Nova e do livro Tarefa), pode ser reconstituída e interpretada por escolhas estéticas que se misturam com protocolos de indexação, mas também dialogam com possibilidades gráficas/editoriais e na interferência de elementos plásticos, como a materialidade das mobílias, do cimento e da luz por trás dos suportes.

Sobre esse último ponto, tem pouco tempo que percebi a relação entre elementos constitutivos dos dois trabalhos e uma questão trivial do trabalho no arquivo do Curro Velho. Iniciei a digitalização dos negativos sem ter disponível um aparelho de scanner apropriado para isso. Entre improvisações com scanners de mesa comuns e usos de mesa de luz para fotografar os negativos e então obter reproduções di- 


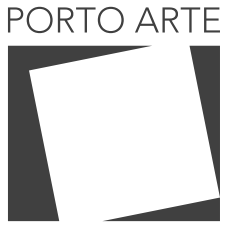

Revista de Artes Visuais

v. 25 n. 43

Jan/jun 2020 e-ISSN: 2179-8001

gitais deles, estavam já se manifestando vários recursos que apliquei na produção dos dois trabalhos. Algumas reproduções do livro Tarefa foram feitas como se ele fosse um negativo fotográfico, como se a polpa do papel fosse tão transparente quanto uma película fotográfica.

GVC:

O público das exposições de arte, em especial de grandes mostras coletivas como o Arte Pará e o Diário Contemporâneo de Fotografia, geralmente assume uma postura imediatista de leitura ou interpretação das obras - cuja quantidade chega mesmo a inviabilizar qualquer leitura mais densa ou demorada, sob pena de não se "terminar" a visita. Há uma série de questões que poderíamos debater, sobre as atuais práticas de exibição e consumo de arte contemporânea. Uma dessas questões é posta por instalações como as tuas: que tipo de experiência com a obra é necessária para que ela seja devidamente "lida" ou "consumida"?

Grande parte do teu trabalho tem características que aproximam as tuas práticas daquelas do pesquisador das ditas ciências humanas: o trabalho com documentos e arquivos, e mesmo a fotografia como registro ou produção de dados. Inclusive, és sociólogo de formação. Me parece que instalações como C Nova Feira e Arar o solo requisitam, do público, uma experiência ativa semelhante a do pesquisador - é preciso mergulhar nos dados que as obras oferecem, decodificar suas muitas camadas, traçar comparações, associações e análises, e daí extrair algo como um significado. Esse "trabalho" que as tuas instalações exigem do espectador me faz pensar sobre as posturas que o mundo da arte contemporânea estimula nos diferentes públicos. Essa é uma questão que tu te colocas? E, também, isso me leva a entender a obra de arte como espaço possível para a produção de "conhecimento científico" (no sentido das ciências humanas). Queria que tu comentasses sobre as aproximações e as diferenças que tu percebes entre a prática artística e o ofício do sociólogo (ou do historiador, do geógrafo e do cientista em geral).
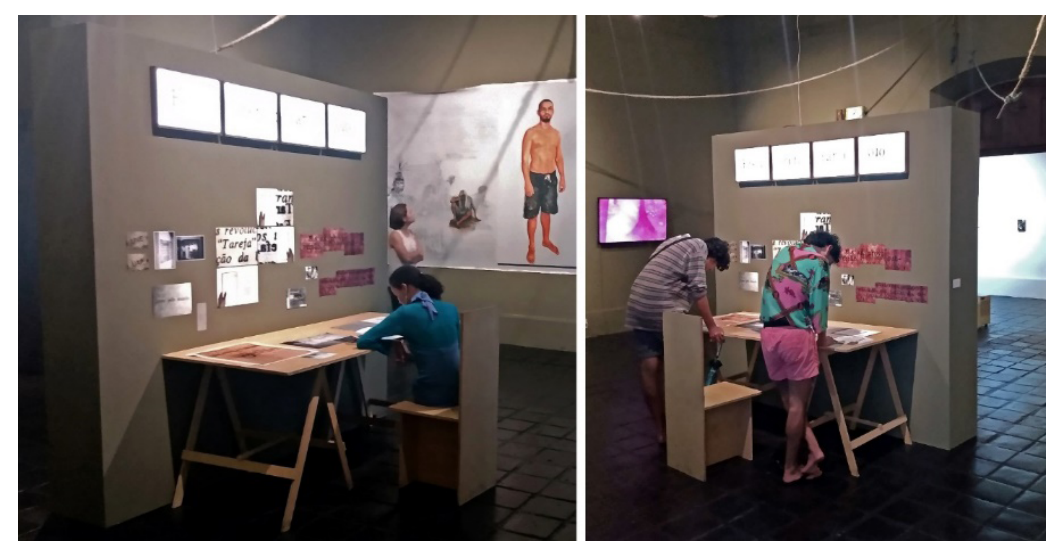

Figura 4: Público experimentando a obra Arar o solo, 2019. Fonte: $38^{\circ}$ Arte Pará, fotografias de Ionaldo Rodrigues. 


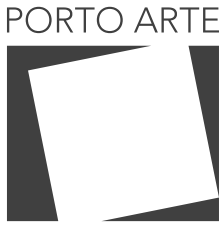

Revista de Artes Visuais

$\vee 25 n .43$

Jan/jun 2020 e-ISSN: 2179-8001

\section{IR:}

Nas visitas que fiz às exposições, percebi que as pessoas no $C$ Nova Feira tendiam a ver o máximo de imagens possíveis na passagem dos slides no projetor, o livro e os outros impressos pareciam ficar em segundo plano. No Arar o solo, a predominância de palavras talvez favorecesse o tempo maior que as pessoas me pareceram dedicar aos livros na mesa, vi grupos folheando os livros e conversando, mas também pessoas que passaram um tempo sozinhas, num ambiente de estudo (fig. 04). Isso formou uma dimensão do trabalho que eu desejava muito que acontecesse. Sendo ele também uma homenagem, o desenho inicial que deu origem ao formato da instalação tinha como referência certo elemento épico que apareceu durante a pesquisa: o relato pessoal de Paes Loureiro sobre a dor que a supressão da leitura e da escrita causaram nos períodos de cárcere e também da importância vital dos momentos em que foi possível ler e ter como escrever nesse mesmo contexto. A passagem da biografia de Paes Loureiro que o coloca como gestor público que implementou, duas décadas depois das prisões por subversão, o Sistema Estadual de Bibliotecas Públicas e a significativa ampliação da Biblioteca Arthur Vianna, complementa essa imagem formadora do trabalho, da escrita/leitura como aragem e semeadura.

Esse breve balanço sobre possíveis limitações e também alcances que as instalações possam ter tido nos espaços e projetos em que elas foram montadas, sistematizado agora por mim a partir da tua reflexão, me coloca a ideia de que talvez as instalações sejam parte de um processo que objetiva abrir pro debate as questões envolvidas na produção de documentos e que estimule a leitura e reprodução deles. De certa forma, o lugar da publicação (impressos, cartazes, zines, livros, etc.) me parece ser o espaço em que realmente o convite feito na instalação será aceito ou não. E aí a reprodução das instalações em publicações me parece algo vital, mas junto de outras coisas, como essa conversa que a gente está tendo e a todos os outros atos reprodutivos que tudo isso possa estimular, como alguém ir emprestar o Tarefa na [Biblioteca] Arthur Vianna ou um editor relançar o livro há muito tempo esgotado.

Sobre a aproximação do conhecimento científico e a prática artística, talvez possa falar algo sobre a minha experiência de formação, acho que existem professores que praticam por décadas a disciplina laboral do artista e também há artistas que pesquisam muito pra poder perceber ou dar corpo ao que ainda não tem nome. A rigor, eu compreendo e reconheço as especificidades que distinguem os ofícios de cientista e artista, mas sou condicionado a fazer isso ocupando um cargo público legalmente ligado a minha formação acadêmica de cientista social, sendo que entre o intervalo dos pontos e contracheques o que eu faço na instituição é fotografar/arquivar, e, apesar de ser em alguns meios reconhecido enquanto fotográfo/artista e em função disso escoar minha produção, nunca ter tido espaço e tempo dedicados exclusivamente ao ofício de artista (com exceção do mês de maio de 2018, em razão do prêmio de residência artística do Diário Contemporâneo). 


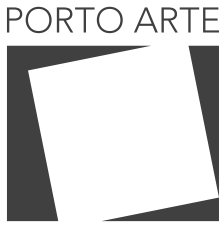

Revista de Artes Visuais

$\vee 25 n .43$

Jan/jun 2020 e-ISSN: 2179-8001

\section{GVC:}

A opção pela instalação artística também implica, geralmente, em uma fotografia não-objetal, no sentido de não resultar em objetos direcionados ao mercado de arte. É evidente que, há muito, as instalações já foram incorporadas ao mercado de arte, mas, em uma cidade como Belém, em que esse mercado é incipiente, optar pela instalação e por esse tipo de uso da fotografia parece um contraponto à lógica predominante no campo artístico local. Essa lógica me parece ser a de uma prática fotográfica que resulta em bens comercializáveis, cujo valor depende sobretudo do estilo do fotógrafo (a "originalidade" do seu olhar) e das características estéticas do objeto-obra (dimensão ou formato, qualidade de impressão/revelação etc.). Tu concordas que haja a predominância desse tipo de fotografia no campo artístico em Belém? As últimas três ou quatro décadas em Belém, que testemunharam um fortalecimento individual e coletivo da fotografia artística especializada, podem oferecer um bom pano de fundo a partir do qual analisar a tua obra.

\section{IR:}

Tenho a impressão de que essa lógica de uma afirmação autoral vinculada a uma formatação de mercado na cena fotográfica local é algo mais recente, vinculada ao momento de euforia emulado nas feiras de arte que nacionalmente tomaram um fôlego no encontro do "crescimento econômico" e nos planos de estímulo à economia criativa e nos escritórios que foram criados para o fortalecimento da arte brasileira no mercado de arte global, tudo isso muito vinculado à política cultural e econômica do lulismo. Nesse período, é bom lembrar, chegou a ser dito, em uma edição especial Bravo! Pará, que ocorria o renascimento da Belle Époque. ${ }^{8} \mathrm{~A}$ capa dessa revista era composta por um trabalho recente, à época, do Luiz Braga. Acho esse um momento exemplar dessa tendência. Outro, que pode dizer algo dessa gestão de marca da "fotografia paraense" nesse mesmo contexto, mas vinculada a esse ideário da coletividade, é a exposição $O$ olhar que vem da terra, realizada na Galeria Virgilio em paralelo a SP-Arte de 2012. Uma coletiva de trabalhos inéditos ou recentes de artistas consolidados em suas produções e que formavam um campo muito diverso, eram então vinculados pelo release e texto curatorial ao discurso padrão do papel da Fotoativa e da ideia essencialista de identidade cultural amazônica enquanto fontes desse "Olhar que vem da terra".

Alguma relação minha com o estudo do materialismo histórico e de teorizações como a do culturalismo de mercado da professora Otília Arantes, sempre colocaram algum distanciamento entre o legado das várias dimensões do campo fotográfico daqui e as tensões e neutralizações que esse mesmo campo sofre da brutal dependência econômica e política em que a região está colocada. No auge do contexto lulista que eu citei acima, nos restou seguir sendo um fornecedor de commodities, e o rebatimento disso na capital [do estado], explicitado num surto imobiliário que aumentou a concentração de torres nas proximidades do centro histórico, fazia os

8- "A Belle Époque é hoje: música pop, gastronomia, ópera, fotografia. O estado vive um período de explosão cultural comparável à época da borracha", na capa de Especial Bravo! Pará, Suplemento parte da revista Bravo!, n. 172, São Paulo: Abril, dezembro de 2011 


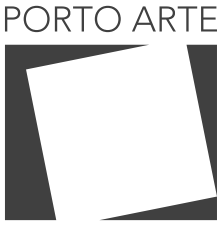

Revista de Artes Visuais

$\vee 25 n .43$

Jan/jun 2020 e-ISSN: 2179-8001

artistas e demais agentes desse incipiente mercado de arte e animação cultural levantarem questões como "de onde vem esse dinheiro todo?", "será que esse pessoal que compra esses apartamentos caros não pode ser educado para comprar obras de arte?". Não demorou para as primeiras respostas a essas perguntas mostrarem que a demanda desses extratos era por algo bem mais essencial: comida e bebida, jambu, cerveja gourmet e derivações.

O impacto que esse movimento todo teve na frágil estrutura institucional local que possibilita alguma zona de formação, aperfeiçoamento, difusão e guarda do campo artístico e cultural é hoje cada vez mais explícito. Eu posso dizer que de 2004 , ano que comecei a fazer as primeiras oficinas de fotografia, até 2016, ano em que um trabalho meu passou a integrar a coleção do Prêmio Diário integrada ao SIM/SECULT, participei ativamente dessa estrutura institucional em todas as quatro linhas que citei antes. Percebo a crescente precarização dessa estrutura, que acompanha uma tendência a centrar no indivíduo "criativo" uma certa livre iniciativa empreendedora que submete ainda mais os produtores, iniciantes ou já experientes, a seguirem demandas de mercado. Isso tem potencial de neutralizar o tipo de produção que se desenvolveu aqui desde a abertura política em meados dos anos 1980 e que ainda aparenta ser muito presente e valorizada. A tendência que isso aponta, na minha visão, é a de colocar tanto o corpo de trabalhos produzidos nesse período numa latência inerte, quanto o processo de formação, central nessa mesma fotografia sensorial do período, numa repetição de procedimentos que já não geram os mesmos efeitos.

\section{GVC:}

Voltando às especificidades da tua produção, me parece que há um uso cuidadoso das palavras e de seus significados, que perpassa boa parte da tua obra. Em certos momentos, essas palavras são tomadas dos vestígios históricos com que tu trabalhas. Outra operação que fazes é a de eleger, como título, palavras com carga semântica capaz de potencializar os objetos visuais (em geral fotográficos) que constituem algumas obras. Em trabalhos estruturados como publicações ou instalações, também trazes citações acadêmicas e textos informativos (como uma ficha de catalogação e um manual de instruções). Quando apresentaste o processo de pesquisa desenvolvido na residência artística em São Paulo, ${ }^{9}$ especialmente na EMPLASA, lembro de ter visto pela primeira vez o teu procedimento de se apropriar, fotograficamente, de palavras existentes em documentação impressa. Depois, em Arar o solo, essa relação com evidências históricas escritas ganha outras dimensões, indo do close fechado em palavras específicas até a fotografia de páginas inteiras, incluindo a mão do fotógrafo-pesquisador - fotos não muito diferentes daquelas que tantos pesquisadores realizam ao tratar com documentos e arquivos institucionais.

\footnotetext{
9- Em 2018, Ionaldo Rodrigues recebeu Prêmio de Residência Artística em São Paulo, concedido pelo IX Prêmio Diário Contemporâneo de Fotografia. Sua estadia em São Paulo durou um mês, sob a tutoria da artista e professora Lívia Aquino. Ionaldo Rodrigues desenvolveu pesquisa no acervo da Empresa Paulista de Planejamento Metropolitano S/A (EMPLASA), e apresentou parte desse processo em Belém, no dia 21 de junho de 2018, em evento promovido pelo Prêmio Diário Contemporâneo de Fotografia.
} 


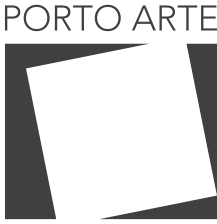

Revista de Artes Visuais

v. 25 n. 43

Jan/jun 2020 e-ISSN: 2179-8001

Figura 5: Ionaldo Rodrigues Drenagem (Bueiro_parte 01), 2010. À esquerda: daguerreótipo, $5,5 \mathrm{~cm} \times 8,5 \mathrm{~cm}$. À direita: fotografia Pinhole em papel fotográfico preto e branco, $4 \mathrm{~cm} \times 4 \mathrm{~cm}$. Fonte: Acervo de Ionaldo Rodrigues, imagens cedidas pelo artista.
Essa dimensão da palavra escrita que tem acompanhado tua produção me parece indicar um tensionamento entre imagem visual e texto verbal. Há palavras escritas que são levadas ao limite de um uso imagético visual, e vice-versa. É um esgarçamento dos signos, que funcionam simultaneamente como texto verbal, texto visual e evidência histórica. Nessa relação entre imagem e palavra, talvez possamos atentar a um terceiro elemento que atravessa ambas: a materialidade. Acho interessante como teus trabalhos manejam a materialidade de um modo que nunca é gratuito. Esse fato inclusive parece ecoar o teu interesse por processos fotográficos históricos, como a cianotipia. As imagens e as palavras habitam em nós (nas nossas interpretações), mas também habitam na matéria dos objetos, e essa materialidade às vezes é, por si só, um signo. É o que percebo ao observar as tuas escolhas recentes, seja destacando a materialidade das coisas fotografadas, seja conferindo uma existência material singular às obras. Já falaste um pouco sobre tudo isso na primeira resposta, agora gostaria que tu comentasses sobre como funciona teu processo criativo, no que diz respeito a essas escolhas de imagem, palavra e materialidade.
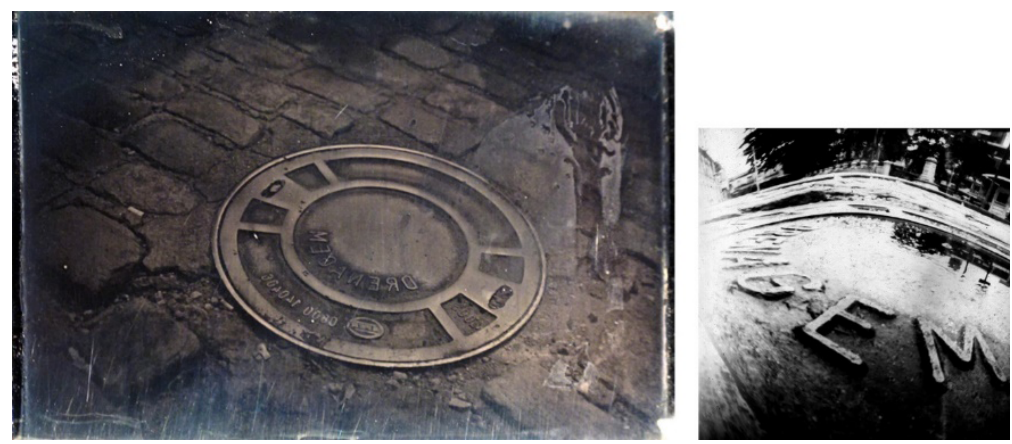

IR:

Talvez o processo ocorra por camadas de trabalho mental e manual que vão se acumulando e ganham uma organização e algum sentido no processo de montagem. 0 trabalho Drenagem me deixou esse caminho disponível, ele é também um balanço pessoal do arquivo que fui montando nos meus primeiros dez anos de produção em fotografia, e é um experimento de autoanálise que eu me permiti pra tentar entender que tipo de fotografia eu fazia e o que eu queria com aquilo.

Esse trabalho pode ser um caminho pra responder a tua pergunta, nele, a palavra drenagem me revelou sentidos que eu extraí primeiramente da materialidade fotográfica (fig. 05). A palavra grafada na tampa do bueiro na Praça das Mercês quando transformada em imagem por dois processos fotográficos distintos (daguerreótipo e fotografia pinhole), foi alterada pela própria natureza dos dois processos, no daguerreótipo a palavra aparece invertida, no pinhole ela aparece com uma grande distorção ótica. Essas duas determinações materiais, a que a mesma palavra foi submetida para virar imagem, são produzidas por uma relação muito abstrata da luz quando traduzida 


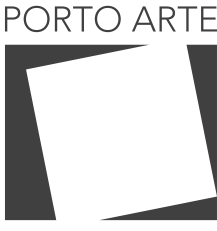

Revista de Artes Visuais

v. $25 n .43$

Jan/jun 2020 e-ISSN: 2179-8001

Figura 6: Ionaldo Rodrigues, Baquirivu, 2018, em edição. Fonte: Acervo de Ionaldo Rodrigues, imagem cedida pelo artista. por elementos da ótica e da química mobilizados nos processos de produção desses artefatos. Essa alteração, esse deslocamento, não planejado de maneira consciente no momento da captura, abriu para mim a percepção do sentido alegórico da palavra drenagem. Os sentidos técnicos de cada processo fotográfico citado nesse trabalho estão sempre tencionados com os possíveis sentidos históricos da materialidade urbana também citada nessa mesma montagem. Essa abertura alegórica da palavra me pareceu uma maneira de trabalhar com documentos sem seguir a progressão linear de uma historiografia positivista, mas por fragmentos das técnicas de controle da água nas cidades e no processamento das imagens fotográficas.

0 trabalho realizado na biblioteca da EMPLASA vai no mesmo caminho (fig. 06). Lá eu trabalhei tendo como base as páginas do Plano Diretor de Drenagem da Bacia do Rio Baquirivu, publicado em 1976. Reproduzi em macrofotografia fragmentos de palavras e imagens do Plano Diretor. Durante a edição desse arquivo de imagens, percebi que a macrofotografia poderia ser um caminho pra tratar as páginas de papel ofício do Plano como um análogo do próprio território da Bacia do Rio Baquirivu, como se esse lugar tivesse sido fotografado por fotografia aérea e as manchas gráficas no papel, as camadas de fotografias coloridas coladas nesse papel com fita durex e a própria estrutura do documento (vincos, tipos de papéis, manchas, tipo de encadernação, etiquetas, etc.) fossem as marcas/legendas que um leitor de um atlas deve buscar compreender.

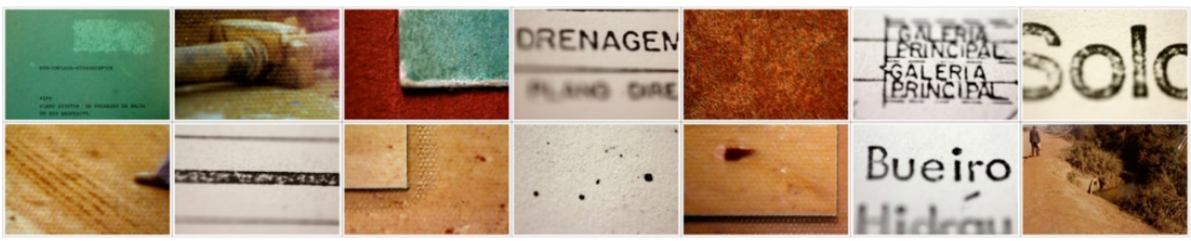

Os processos desses dois trabalhos, que eu tentei apresentar com ênfase no processo de edição, onde entram questões que eu não formulei de maneira consciente no momento da captura, são influenciados por referenciais e ideias que ficam em latência e ganham algum sentido quando um elemento daquele grupo de imagens me coloca possibilidades. Eu acho que a palavra/imagem tem sido esse elemento que me permite trabalhar tanto com o caráter documental do que preexistiu para se tornar imagem (o bueiro na Praça das Mercês e a produção do plano sobre um rio em Guarulhos), quanto com os sentidos alegóricos que podem vir do retorno desses mesmos elementos deslocados e reapresentados.

\section{GVC:}

Observando a tua produção de modo geral, me parece nítida a tensão entre ser humano versus natureza, artificial versus orgânico, que atravessa muitos trabalhos. O humano, aqui, pode ser entendido como um determinado projeto de humanidade, que a gente herda da invasão ocidental, com seus modelos de cidade, sua concepção de paisagem, suas relações com o mundo natural, a modernidade. A leitura que faço é de que muitos trabalhos rastreiam esses embates humano $x$ natureza, encarando as 


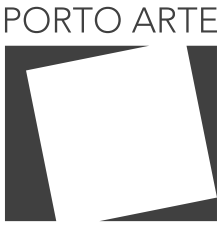

Revista de Artes Visuais

V. $25 \cap .43$

Jan/jun 2020 e-ISSN: 2179-8001
Figura 7: Ionaldo Rodrigues, Progresso LTDA, Botânica do Asfalto (série). 2007 Cianótipo. Fonte: Acervo de Ionaldo Rodrigues, imagem cedida pelo artista sobras, o "rebotalho", como vestígios capazes de escancarar essa relação conflituosa. Em Botânica do Asfalto, Arrabalde, ${ }^{10}$ Drenagem, Rebotalho ${ }^{11}$ e Pedra de Raio ${ }^{12}$ essa questão é mais central, mas mesmo em C Nova Feira ela também pulsa, na relação entre mata nativa, árvores ornamentais e planta-baixa arquitetônica.

Arar o solo torna a questão mais sutil, porque esta obra gira em torno de questões políticas e da própria figura do Paes Loureiro, mas o verso que destacas da poesia dele não deixa de apontar para essa operação. A tarefa de arar o solo, revolver a terra e lhe preparar para a cultura, é como a tarefa do poeta, e é como a tarefa do artista/ fotógrafo/historiador, que revira ao avesso esse chão e procura e expõe as marcas dos diferentes tempos que a superfície das coisas esconde.

Evidente que as interpretações das tuas obras podem ser muito amplas, mas queria saber se podes comentar duas dimensões interligadas que talvez sejam intencionais: primeiro, teu trabalho como exercício de crítica à modernidade ocidental e aos seus desdobramentos nas cidades brasileiras/amazônicas; e, depois, um comprometimento ecológico ou ambientalista (distante das concepções mais estereotipadas desses termos, é claro).

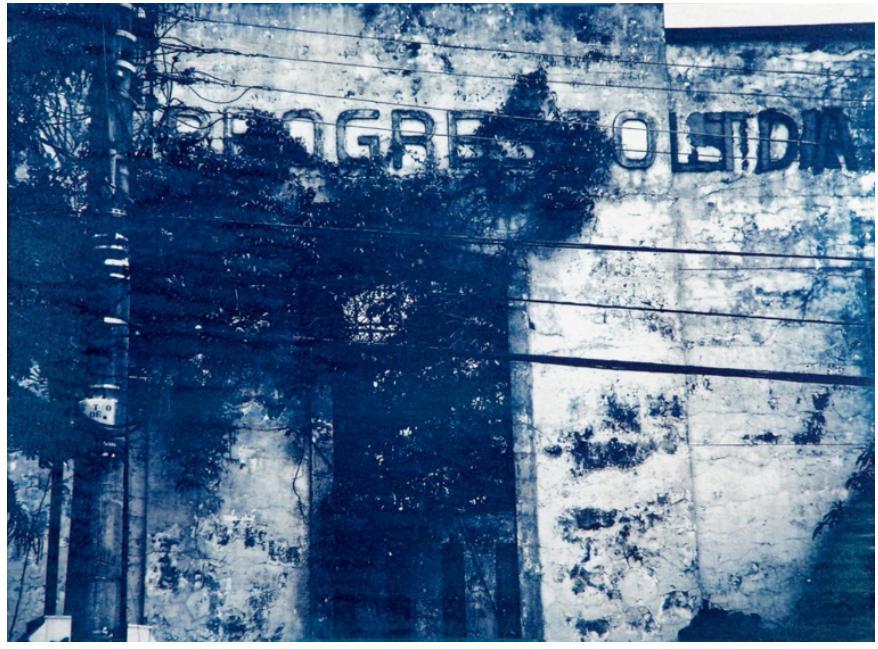

10- Arrabalde (2012 / 2015) é um ensaio fotográfico analógico em preto e branco que reúne retratos de fachadas e quintais, junto a paisagens no entorno desses locais retratados. As imagens foram feitas no município de Altamira (PA) e nos bairros do Reduto, Umarizal, Condor e Cidade Velha em Belém (PA). Fo editado na revista Gotaz, n. 1. Belém: Gotazkaen Estúdio, 2012, disponível em: <https://issuu.com/gotaz/ docs/revista_gotaz_final_web>. Em 2015 também foi editado como publicação pelo selo Prova Impressa. 11- Rebotalho (2015) reúne fragmentos de ensaios e imagens avulsas produzidas em diversos formatos de 2006 até 2015. Estruturou: uma exposição individual, realizada na Galeria Kamara Kó, em 2015, com a curadoria de Mariano Klautau Filho; um protótipo de livro, produzido em 2015, que integra a Biblioteca do Prêmio Diário Contemporâneo de Fotografia / Biblioteca do Museu da Universidade Federal do Pará; e uma publicação virtual/blog, disponível em: <https://rebotalho.tumblr.com/>.

12- Pedra de Raio (2017) é uma publicação fotográfica que trata da Ilha do Marajó, no Pará, trazendo registros fotográficos da paisagem e da sociedade no local. Traz algumas citações de textos sobre a Ilha do Marajó e sobre os chamados tesos marajoaras, vestígios das civilizações que ocuparam a região antes da colonização europeia. Traz, também, um texto informativo sobre a crença da pedra de raio, na população do Marajó, que diz respeito a uma pedra que afunda na terra e retorna à superfície após sete anos, voltando então a atrair raios em sua direção. 


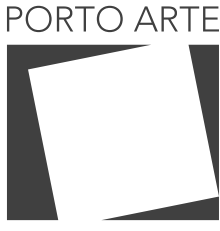

Revista de Artes Visuais

v. 25 ก. 43

Jan/jun 2020 e-ISSN: 2179-8001

IR:

Esse realmente é um eixo que acompanha vários trabalhos. Foi o primeiro de um ensaio que pude propor como linha de experimentação na "Bolsa de pesquisa em arte" do finado Instituto de Artes do Pará em 2007, no projeto que iniciou o trabalho Botânica do asfalto (fig. 07).

A recorrência dessa discussão nos trabalhos deve estar ligada ao caráter de síntese que ela tem. Vários debates e produções que acompanhei na graduação em Ciências Sociais partem da investigação da Modernidade e do processo civilizatório, profundamente marcados pelo contexto europeu, mas colocados em perspectiva pelas pesquisas realizadas pelos professores da universidade em que estudei. Na Fotoativa eu pude ter um espaço de formação que colocava a tradição da história da fotografia, também radicalmente ocidental, em uma abordagem sensorial e analítica. Eu lembro de ler os textos da Susan Sontag durante a oficina Photomorphosis, conduzida pelo Miguel Chikaoka, e a crítica que ela faz sobre certa atrofia das potencialidades da fotografia em um mundo-imagem e também a reivindicação por uma ecologia da imagem, aquilo tudo ganhava uma clareza grande na abertura do processo que o Miguel propunha, também enquanto crítica dos excessos e do fetichismo do mercado fotográfico.

Alguns dos encontros mais instigantes entre esses dois campos da minha formação, o pensamento social e a fotografia, ocorreram tomando como base as relações entre cultura/história e natureza. Ver as imagens e ouvir o relato da Paula Sampaio ${ }^{13}$ sobre a pesquisa amazônica que ela realiza há décadas e ler os textos do Ernani Chaves ${ }^{14}$ sobre o trabalho da Paula é um desses encontros, nesse movimento eu percebi que há toda uma historiografia da Amazônia em curso, sendo produzida a partir de documentos visuais. A pesquisa do Patrick Pardini ${ }^{15}$, no arquivo fotográfico e textual que ele está montando também há décadas, é outro exemplo desse diálogo, considerando que o Patrick emparelha em sincronia a fotografia e o pensamento dele com um debate científico em profunda transformação, justamente a teorização sobre as evidências arqueológicas, etnográficas e ecológicas das "matas culturais" e dos "solos antropogênicos".

É então como estudante dessa produção em teoria e imagem que eu também busco mobilizar essa relação entre cultura e natureza nos meus trabalhos. Tentando contribuir num movimento que eu fui percebendo nessas fontes desde os primeiros contatos, a proposição de uma teoria-imagem e a abertura de uma alteridade cultura/história-natureza.

GVC:

Quero destacar outra característica perceptível em tuas obras - em especial nas instalações Arar o solo e C Nova Feira. Me parece que esses trabalhos estão

\footnotetext{
13- Nascida em Belo Horizonte (MG), em 1965, vive e trabalha em Belém. Seus trabalhos podem ser conferidos em seu site pessoal, disponível em: <http://paulasampaio.com.br/projetos/>. 14- Ernani Chaves, "Na estrada da vida: a transa-amazônica de Paula Sampaio", Cinética, v. 1, p. 16, 2007. Disponível em: <http://www.revistacinetica.com.br/cep/ernani_chaves.htm>.

15- Patrick Pardini, "Natureza e cultura na paisagem amazônica: uma experiência fotográfica com ressonâncias na cosmologia ameríndia e na ecologia histórica", Boletim do Museu Paraense Emílio Goeldi. Ciências Humanas, v. 7, n. 2, Belém: MPEG, maio-ago. 2012, p. 589-603. Disponível em: <http://www.scielo.br/ $\mathrm{pdf} /$ bgoeldi/v7n2/v7n2a17.pdf $>$.
} 


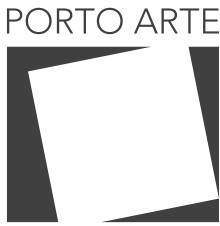

Revista de Artes Visuais

v. 25 ก. 43 Jan/jun 2020 e-ISSN: 2179-8001
Figura 8: Detalhe da instalação Arar o solo, Ionaldo Rodrigues, 2019.Fonte: $38^{\circ}$ Arte Pará fotografia de Gil Vieira Costa dentro daquilo que tem sido definido como crítica institucional, obras que usam o espaço social das instituições para desvelar suas próprias engrenagens, subterfúgios e relações de poder.

Em C Nova Feira, a tua manobra articula o Curro Velho, onde és servidor público, e o Grupo RBA de Comunicação, da família de Jader Barbalho, ao qual estão vinculados o jornal Diário do Pará e o Prêmio Diário Contemporâneo de Fotografia, em que a instalação foi inscrita e selecionada. 0 trabalho expõe a política (ou a falta dela) de arquivo e salvaguarda de uma instituição cultural do estado. Também usa a mostra de arte contemporânea da empresa de Jader Barbalho para trazer imagens do passado político do Pará em que ele era um dos personagens.

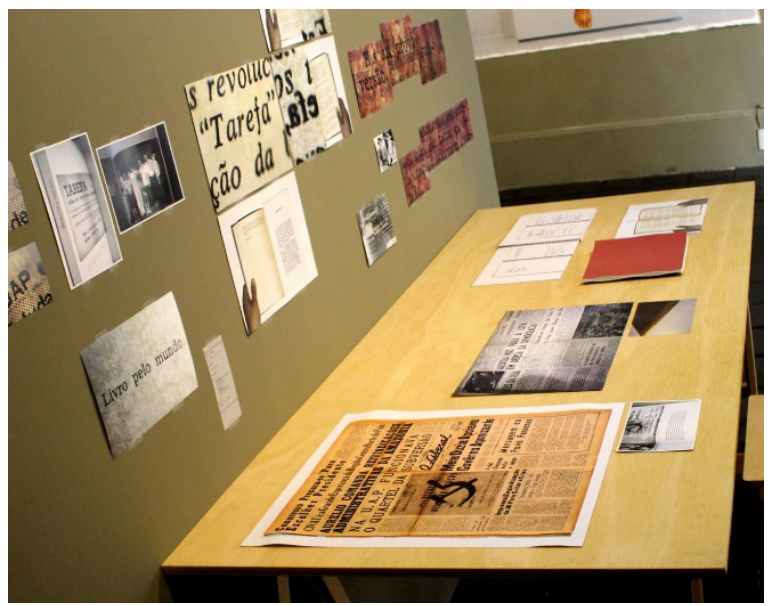

Arar o solo, por sua vez, foi pensada na condição de artista convidado do Arte Pará, mostra de arte contemporânea do Grupo Liberal e da Fundação Rômulo Maiorana. A tua homenagem ao Paes Loureiro joga luz sobre um episódio bastante recuado no tempo, quando esse intelectual sofreu perseguição política e teve a edição de seu primeiro livro confiscada e destruída, nos idos do golpe civil-militar de 1964 . 0 jornal 0 Liberal publicou, à época, matéria sensacionalista sobre o fato, incluindo a reprodução de um cartaz falso - fato retomado em livro, que tu habilmente recolocas no debate público por meio da instalação (fig. 08).

A perspectiva de uma crítica institucional talvez não seja o centro dessas obras, sendo apenas um de seus componentes. Em todo caso, queria saber as tuas considerações a respeito, e pedir que comentes um pouco sobre esse jogo com as instituições e com os interesses (dissonantes) dos muitos personagens envolvidos nessas tramas.

IR:

No C Nova Feira esse elemento que destacas já se colocava na decisão de inscrever o trabalho no Prêmio Diário e, caso o trabalho fosse selecionado, tirar os slides do arquivo audiovisual do Curro Velho e levar para a montagem do trabalho no Museu do Estado. No Arar o Solo, recebido o convite da curadoria, iniciei a pesquisa para a pro- 


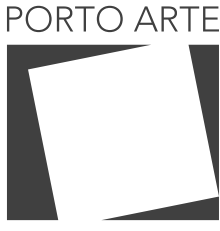

Revista de Artes Visuais

v. 25 ก. 43

Jan/jun 2020 e-ISSN: 2179-8001

dução do trabalho, a capa do jornal me apareceu no meio dela e então decidi colocar o fac-símile da capa na montagem final do trabalho. Em ambos os casos, contei com a autonomia do júri de seleção do Prêmio Diário e da curadoria do Arte Pará pra levar a frente as proposições. Acredito que o posicionamento dos dois grupos de profissionais do campo artístico atuantes nesses casos venha da seriedade e do comprometimento das pessoas envolvidas nesse processo, no entanto, desconfio que, assim como eu (no caso do Curro Velho), eles também contavam com a total indiferença ou mesmo invisibilidade de elementos de um trabalho artístico no meio do ecossistema patronal e político no qual estavam as respectivas empresas financiadoras dos projetos de arte a qual eles prestavam serviço enquanto artistas e pesquisadores qualificados, e eu também contava com a mesma indiferença dos gestores do órgão em que trabalho como servidor público.

Eu tenho dúvidas se o desfecho seria o mesmo, caso, tanto eu quanto eles, tivéssemos consultado antes nossos "chefes", talvez isso desse início a grandes constrangimentos entre nós.

GVC:

Por fim, os temas da crítica à modernidade, do comprometimento ambientalista e da crítica institucional me levam à noção de engajamento social ou político, também pertinente pra discutir a tua produção. Há uma carga política no teu trabalho, que em algumas obras (como Arar o solo) ganha contornos muito vívidos. Essa politização aparece nas opções temáticas, que discutimos na questão anterior. Por outro lado, as tuas instalações recentes levam esse engajamento político a um patamar diferente, já que oferecem ao público a própria experiência do arquivista/historiador/sociólogo, transformando o espectador em um tipo de pesquisador.

A questão que quero te colocar é sobre como tu avalias as contradições de uma produção artística socialmente engajada, especialmente no campo da arte contemporânea especializada. De início, os públicos aos quais as obras se destinam, os artistas optando por trabalhar com questões internas do campo artístico e/ou com questões mais abertas a públicos não especializados. Depois, as contradições de uma produção que atua dentro de um campo social bastante atrelado à lógica do atual estágio do capitalismo, seja no que diz respeito à especulação e financeirização no mercado de arte, no papel que a arte contemporânea mainstream exerce para a acumulação de capital, na sua instrumentalização para marketing cultural de grandes empresas, ou, ainda, na simples (mas nem sempre verdadeira) condição desse campo social como espaço elitista e de distinção simbólica.

\section{IR:}

A tua questão me fez querer reler o texto da conferência que Walter Benjamin pronunciou em 1934, na França, no Instituto para o Estudo do Fascismo, o título desse texto é "O autor como produtor"16, e lembro de uma vez a gente ter conversado rápido sobre ele, sobre a questão do "mecenato ideológico". 


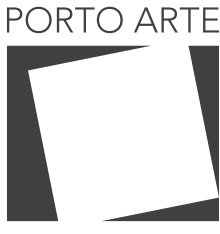

Revista de Artes Visuais

v. 25 ก. 43

Jan/jun 2020 e-ISSN: 2179-8001
Foi importante reler esse texto agora, vejo que várias questões dele formaram o meu entendimento do que eu tentei falar até aqui. É o materialismo dele que anima a importância que eu passei a dar, na minha produção, aos impressos, à editoração e à possibilidade de colocar as fotografias e as palavras à prova de um outro tipo de circulação e exibição. Esse lugar, amplia a importância das relações que o produtor de arte mantém com atividades de formação de outros produtores, tanto no nível técnico quanto conceitual. 0 convite à apropriação dos trabalhos, que eu faço ao visitante da exposição e que tu destacou como possibilidade do público passar de espectador à pesquisador, é também uma tentativa, um desdobramento que no meu trabalho com imagens ocorre também quando eu eventualmente ministro uma oficina, um curso, ou mesmo quando, na prática de arquivista, busco disponibilizar em mídia digital o acervo da instituição em que trabalho com o desejo de ver aquilo ser ativado nas oficinas que são realizadas lá e nos outros usos possíveis que aqueles documentos portam. 0 alcance político disso, eu creio que está naquela pergunta reiterada pelos moradores de Bacurau mais de uma vez durante o filme [homônimo]: "Vocês já visitaram o museu da cidade?"

Sobre as contradições da produção artística socialmente engajada, são amplas e alcançam todos os matizes de contradições que o capitalismo impõe, mesmo quando acolhe as manifestações de contestação aos seus efeitos, principalmente se essa contestação "abastece um aparelho produtivo, sem modificá-lo", é o que Benjamin destaca sobre a possibilidade de estetização da arte engajada se o processo de produção dessa arte não busca alterar separações entre trabalho manual e intelectual, por exemplo, ou ainda, na crítica à reivindicação de um espaço totalmente autônomo para lidar com as questões do espírito, da inteligência, das ideias. 0 que eu sinto é que na arte contemporânea isso se manifesta em produções com apelo espetacularizado de denúncia moral das injustiças sociais ou opressões direcionadas, mas isso é envolto numa estrutura de culto ao produto artístico como se esse pudesse ser alheio à historicidade, inclusive de seu caráter de mercadoria na estrutura que você analisou na formulação da questão, ou então apartidário, livre das "questões menores" que envolvem estruturas políticas ou institucionais. Essa estrutura toda da arte contemporânea, irmã geracional da queda do muro de Berlim e da filosofia pós-moderna, começa a lembrar o art nouveau na belle époque que precedeu a I Guerra Mundial. Em 2020, aquecimento global, pandemia e supremacistas brancos já começam a despertar a gente desse sonho onde às vezes parece difícil distinguir o Itaú Cultural da Mídia Ninja, já que ambos fomentam um aparelho produtivo/cultural, sem modificá-lo, um com dinheiro, outro com views e likes, ambos com mecenato ideológico. 


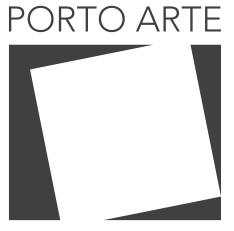

Revista de Artes Visuais

v. $25 \mathrm{n} .43$

Jan/jun 2020

e-ISSN: 2179-8001
Texto recebido em: 15/06/2020

Texto aceito em:25/06/2020

Texto publicado em: 30/06/2020

\section{Gil Vieira Costa}

Doutor em História (2019) e Mestrado em Artes (2011) pela Universidade Federal do Pará. Professor da Faculdade de Artes Visuais da Universidade Federal do Sul e Sudeste do Pará, em Marab, Brasil.

\section{Ionaldo Rodrigues}

Artista contemporâneo atuante no campo da fotografia. Graduado em Ciências Sociais (2008) pela Universidade Federal do Pará. Servidor técnico da Fundação Cultural do Pará, em Belém. 